\title{
Genetic Mapping of Two New Blood Pressure Quantitative Trait Loci in the Rat by Genotyping Endothelin System Genes
}

\author{
Alan Y. Deng, Howard Dene, Michel Pravenec, ${ }^{*}$ and John P. Rapp \\ Department of Physiology and Biophysics, Medical College of Ohio, Toledo, Ohio 43699; and *Institute of Physiology, \\ Czech Academy of Sciences, Prague, Czech Republic
}

\begin{abstract}
The endothelin system, consisting of a series of potent vasoconstrictor peptides and their receptors, is potentially important in the control of blood pressure. We found that the gene coding for endothelin-2 (ET2), also known as vasoactive intestine peptide, cosegregated strongly with systolic blood pressure in a $F_{2}$ population $\left[F_{2}(S \times L E W)\right]$ derived from a cross of the Dahl salt-sensitive (S) rat and the Lewis (LEW/NCrlBR) (LEW) rat. The ET2 locus was assigned to rat chromosome 5. The testis-specific histone (HITH) locus also strongly cosegregated with blood pressure in the $F_{2}(S \times L E W)$ population and was assigned to rat chromosome 17. Genetic maps of the regions containing the quantitative trait loci (QTL) for blood pressure on chromosomes 5 and 17 were constructed and the QTL were localized using the MAPMAKER/QTL program. The rat genes for endothelin-1, endothelin-3, and endothelin receptor A did not cosegregate with blood pressure in several $F_{2}$ populations tested and were assigned to rat chromosomes 17,3 , and 19 , respectively. Endothelin receptor B cosegregated weakly with blood pressure and was provisionally assigned to rat chromosome 15. We conclude that, in the rat, one new blood pressure QTL is located on chromosome 5 marked by the ET2 locus and another new QTL is located on chromosome 17 near the HITH locus. (J. Clin. Invest. 1994. 93:2701-2709.) Key words: rat chromosomes $\bullet$ angiotensin $\mathrm{II}$ receptor $\mathrm{AT}_{1} \bullet$ hypertension • salt sensitivity
\end{abstract}

\section{Introduction}

The rat provides an informative animal model for the study of hypertension, the most common of all human diseases (1). To identify the quantitative trait loci (QTL) ${ }^{1}$ controlling blood pressure, we have been utilizing a candidate gene approach (2-9). The members of the recently discovered endothelin system are obvious candidates (10-15). Endothelin (ET) isopeptides (ET1, ET2, and ET3) are potent vasoconstrictors encoded

Address correspondence to Dr. Alan Y. Deng, Department of Physiology and Biophysics, Medical College of Ohio, P.O. Box 10008, Toledo, OH 43699.

Received for publication 15 December 1993 and in revised form 2 February 1994.

1. Abbreviations used in this paper: $\mathrm{ANF}$, atrial natriuretic factor; $\mathrm{ET}$, endothelin; ET1, ET2, and ET3, ET isopeptides 1, 2, and 3; ETA and ETB, ET receptors A and B; GLUTB, glucose transporter, brain; LOD, base 10 logarithm of the odds favoring linkage; PRL, prolactin; QTL, quantitative trait locus; SSR, simple-sequence repeat.

J. Clin. Invest.

(c) The American Society for Clinical Investigation, Inc.

$0021-9738 / 94 / 06 / 2701 / 09 \$ 2.00$

Volume 93, June 1994, 2701-2709 by three separate genes. Similar to the renin-angiotensin system (16), it is known that ETs are synthesized as inactive preproendothelins which are processed through activation steps by proteases to finally become active. The effects of ETs are mediated through receptors (e.g., endothelin receptors A [ETA] and B [ETB]) located on the cell membrane. The genes for human ETs and ETA have been assigned to human chromosomes (17-20). In a genetic study, ET1 did not cosegregate with blood pressure in human populations (21), suggesting that ET1 may not be involved in the genetic regulation of blood pressure in the human populations tested. In the rat, ET3 was found to cosegregate with systolic blood pressure in a backcross population having a very permissive genetic background, i.e., $F_{1}(S \times R) \times S(22)$, implying that the ET3 or a closely linked locus may be important in the genetic control of blood pressure in this particular backcross. In the current work, we systematically tested the genes for all the known members of the endothelin system for cosegregation with blood pressure in several informative $F_{2}$ populations derived from Dahl salt-sensitive rats and various contrasting strains. In addition, known genes of the endothelin system were localized onto rat chromosomes.

\section{Methods}

Animal procedures. Rat strains used and animal procedures were given in detail previously $(7,23)$ and are only summarized briefly here. The inbred Dahl salt-sensitive (SS/Jr) and inbred Dahl salt-resistant (SR/Jr) rats (24) were used and designated as $S$ and $R$, respectively. To generate segregating $F_{2}$ populations, $S$ rats were crossed with various contrasting strains and the $F_{1}$ offspring were intercrossed to produce $F_{2}$. The contrasting strains included Spontaneously Hypertensive rats, Wistar Kyoto rats, and Brown Norway rats obtained from Harlan Sprague Dawley (Indianapolis, IN); Milan Normotensive rats obtained from Vincent Gattone (University of Kansas); Albino Surgery obtained from C. Heatherington (National Institute for Medical Research, The Rigeway, Mill Hill, UK); and Lewis (LEW/NCrlBR) obtained from Charles River Breeding Laboratory (Wilmington, MA).

$\mathrm{F}_{2}$ rats were weaned at $30 \mathrm{~d}$ of age and fed on high salt $(8 \% \mathrm{NaCl})$ diet (TD82050; Teklad, Madison, WI) starting at $37 \mathrm{~d}$ of age. Systolic blood pressure was measured by the tail cuff microphonic manometer method with the rats warmed to $28^{\circ} \mathrm{C}$ either under light ether anaesthesia or in the conscious restrained state (IITC Inc., Woodland Hills, CA). When the highest blood pressures of rats in the population reached over $200 \mathrm{mmHg}$, the blood pressure of the entire population was measured intensively during a 7-10-d period. At least three consistent blood pressure readings at a given session were acquired and averaged as that session's reading. Three such separate sessions on different days were conducted for each rat. The blood pressure from three sessions was then averaged and taken as the final blood pressure measurement of that rat. All rats were males except that in the crosses with $R$ rats both male and female rats were studied. Data from males and females were combined in the present analysis.

Generation of polymorphic markers containing simple-sequence repeats (SSR) for each member of the ET system. DNA probes specific for each gene of the endothelin system were produced by PCR using primers based on published sequences (11-15). The sources of DNA 
Table I. PCR Primers Used in the Genetic Analysis of the ET System

\begin{tabular}{|c|c|c|c|c|c|c|}
\hline Locus & Chromosome & Use & $\begin{array}{c}\text { Gene Bank } \\
\text { accession } \\
\text { number }\end{array}$ & Primers $\left(5^{\prime} \rightarrow 3^{\prime}\right)$ & $\begin{array}{l}\text { Expected } \\
\text { size }\end{array}$ & Strain comparison of PCR products \\
\hline & & & & & $b p$ & \\
\hline \multirow[t]{2}{*}{ ACRM } & 17 & SSR & M16408 & GACACTGGGATGAGTAGACA & 200 & $\mathrm{BN}=\mathrm{S}>\mathrm{MNS}=\mathrm{LEW}=\mathrm{WKY}>\mathrm{SHR}$ \\
\hline & & & & GGGGGAAAAAGAGAAGAGATGG & & \\
\hline \multirow[t]{2}{*}{ ALPH2 III } & 3 & SSR & L19348 & GAACCGAACAGTGTAGAGACC & 303 & $\mathrm{~S}=\mathrm{MNS}>\mathrm{WKY}$ \\
\hline & & & & TGTGCGTCATTCTGTGGAGACC & & \\
\hline \multirow[t]{2}{*}{ ALPH2 III } & 3 & *SSR & U02088 & GTAATGGAATCTGATGCCCTC & 290 & $\mathrm{~S}=\mathrm{MNS}>\mathrm{WKY}$ \\
\hline & & & & TATTTATCCAGTCCCCTTCAGG & & \\
\hline \multirow[t]{2}{*}{ ANF } & 5 & SSR & J03267 & CAGCACTGAGGATGGAAACA & 230 & WKY $>$ S $=$ MNS $=$ LEW \\
\hline & & & & GAACACAAACAGGCAGTCTACC & & \\
\hline \multirow[t]{2}{*}{ ANF } & 5 & SSR & K02062 & TCCACAACCTTGATCTTTCG & 300 & $\mathrm{~S}=\mathrm{MNS}=\mathrm{LEW}>\mathrm{WKY}$ \\
\hline & & & & ACAGTGAGAGGGATTCGTGA & & \\
\hline \multirow[t]{2}{*}{ AT1 } & 17 & *SSR & (Murphy) & GTATCAGAGTGATTCTGGCTCC & 295 & $\mathrm{BN}>\mathrm{S}=\mathrm{MNS}=\mathrm{WKY}=\mathrm{SHR}>\mathrm{LEW}$ \\
\hline & & & & CСTTCTAGTTTACACGTTGC & & \\
\hline \multirow[t]{2}{*}{ AT1 } & 17 & *SSR & (Murphy) & GAGCAACGTGTAAACTAGAAGG & 265 & $\mathrm{~S}>\mathrm{LEW}=\mathrm{AS}=\mathrm{BN}$ \\
\hline & & & & CAGCTTGAAGTGTTGAAGATGG & & \\
\hline \multirow[t]{2}{*}{ CAT } & 3 & SSR & M11670 & CTTATGTTACCTCACAGCCTGG & 315 & SHR $>$ S $>$ LEW \\
\hline & & & & GGAAGACATGATCCAAGTATGG & & \\
\hline \multirow[t]{2}{*}{ D1A } & 17 & *SSR & U02089 & CTGTGTTAGCGTTGAGTAGACC & 215 & $\mathrm{~S}=\mathrm{MNS}=\mathrm{LEW}=\mathrm{WKY}>\mathrm{BN}$ \\
\hline & & & & TGCAAGTGAACAGAGACCTG & & \\
\hline \multirow[t]{2}{*}{ ELA } & 5 & SSR & L00118 & GGGATTGAGTAAGTCACTGG & 239 & LEW > S \\
\hline & & & & CAAAGTGGGTTTCAGGACAG & & \\
\hline \multirow[t]{2}{*}{ ET1 } & 17 & Probe & M64711 & CCTTGAAAGACTTACTTCCC & 550 & \\
\hline & & & & TTGCTACCAGCGGATGCAAACG & & \\
\hline \multirow[t]{2}{*}{ ET2 } & 5 & Probe & M65200 & ATGGAGCAACCAGCCTCGGCA & 129 & \\
\hline & & & & AGTGTTCACCCAGATGATGTCC & & \\
\hline \multirow[t]{2}{*}{ ET3 } & 3 & Probe & S39779 & GCCAGTTCCAGAAAGTTC & 253 & \\
\hline & & & & ATCCACCGCAGAAGCAAGAA & & \\
\hline \multirow[t]{2}{*}{ ETA } & 19 & Probe & M60786 & CCCATGAATGGAACGAGTATCC & 192 & \\
\hline & & & & GACAAAAAGCAGGGGAGAGACC & & \\
\hline \multirow[t]{2}{*}{ ETB } & 15 & Probe & X57764 & CGTTTGAGGAAAAACAGTCC & 405 & \\
\hline & & & & AATGTAAGTGGGCTGTGAGTG & & \\
\hline \multirow[t]{2}{*}{ ET1 } & 17 & *SSR & U02090 & TGCAGGGTGATTACACAC & 216 & $\mathrm{~S}=\mathrm{MNS}>\mathrm{WKY}>\mathrm{LEW}=\mathrm{BN}$ \\
\hline & & & & GAAGAGTCCTTTTCCTAGCTG & & \\
\hline
\end{tabular}

were as follows: a lambda gt 11 cDNA library made from $S$ kidneys was used to generate probes for ET1, ET3, and ETB; the genomic DNA of S rats was used to generate probes for ET2 and ETA. The PCR primers used to produce the probes are listed in Table I. PCR conditions were given previously (7).

After PCR amplification, these probes were separated on a $1.5 \%$ agarose gel, excised, purified using glass milk (BIO 101, La Jolla, CA), subcloned into a PCR TA II vector (Invitrogen, San Diego, CA) and sequenced with a Sequenase kit (United States Biochemical, Corp., Cleveland, $\mathrm{OH}$ ) to confirm that the sequences of the PCR products were the same as those published. The probes were then used to screen a rat genomic library.

A genomic library (courtesy of Dr. D. Ginn [25]) of the Dahl salt-resistant (R) rat was constructed using lambda GEM-11 Bam H1 arms (Promega Corp., Madison, WI) ligated with size-fractionated genomic DNA partially digested with MboI. This procedure minimized insertto-insert ligation and enabled the formation of ligation products containing mostly single inserts with the vector arms. Recombinants were then packaged using Packagene Extract (Promega Corp.) and plated onto the ER1647 strain of Escherichia coli.

For genomic library screening, a DNA probe was labeled by using a kit for random priming (Boehringer Mannheim Biochemicals, Indianapolis, IN), purified using a Bio-6 column (Bio-Rad, Mellville, NY) and used to screen the $\mathrm{R}$ rat genomic library. Standard procedures for growing phage, screening by filter lift, treatment of DNA on the filters, and hybridization were used (26). The prehybridization and hybridization solutions consisted of $5 \times$ SSPE, 1\% SDS, 10× Denhardt, 0.05 $\mathrm{mg} / \mathrm{ml}$ of salmon sperm DNA, $50 \%$ formamide, $\mathrm{pH}$ 7.4. Hybridization took place at $42^{\circ} \mathrm{C}$ overnight. Washing conditions were $2 \times$ SSC, $1 \%$ SDS, twice at room temperature $5 \mathrm{~min}$ each, followed by $0.2 \mathrm{SSC}, 1 \%$ SDS, twice at $68^{\circ} \mathrm{C}, 30-60$ min each.

Phage was prepared in a NZCYM liquid medium by a standard method (26). The inserts were cut separately with a series of restriction enzymes that cut the vector only once. The digested fragments were then separated on a $1 \%$ agarose gel, transferred to a sheet of Duralonultraviolet membrane (Stratagene, Inc., La Jolla, CA), fixed by ultraviolet cross-linking and probed with a mixture of $(C A)_{15}$ and $(C T)_{15}$ oligonucleotides. The oligonucleotides were end-labeled with ${ }^{32} \mathrm{P}$ as described previously (7). The prehybridization solution was made up of $5 \times$ SSPE, $1 \%$ SDS, $10 \times$ Denhardt, and $0.05 \mathrm{mg} / \mathrm{ml}$ of salmon sperm DNA. The hybridization solution contained $5 \times$ SSPE and $1 \%$ SDS. The hybridization was carried out at $70^{\circ} \mathrm{C}$ overnight. The washing conditions were as follows: twice at room temperature, 5 min each time; and once at $70^{\circ} \mathrm{C}$ for $10 \mathrm{~min}$. The washing solution was the same as the hybridization solution.

The genomic fragments recognized by the $(C A)_{15}$ and/or $(C T)_{15}$ oligonucleotides were then subcloned into a pT7T3 18U (Pharmacia, Inc., Piscataway, $\mathrm{NJ}$ ). The subcloned fragments containing $(\mathrm{CA})_{\mathrm{n}}$ and/ 
Table I. (Continued)

\begin{tabular}{|c|c|c|c|c|c|c|}
\hline Locus & Chromosome & Use & $\begin{array}{l}\text { Gene Bank } \\
\text { accession } \\
\text { number }\end{array}$ & Primers $\left(5^{\prime} \rightarrow 3\right)$ & $\begin{array}{l}\text { Expected } \\
\text { size }\end{array}$ & Strain comparison of PCR products \\
\hline ET2 & 5 & *SSR & U02091 & $\begin{array}{l}\text { AGCTGCCAGACTGAACTGT } \\
\text { GCTGTTGACCAAAGGTATTGGG }\end{array}$ & 206 & LEW $>$ S $=$ MNS $>$ WKY \\
\hline ET3 & 3 & *SSR & U02092 & $\begin{array}{l}\text { GCCTGCATTCATCTTCATCTGC } \\
\text { AAAGGTGGAACTCGCCCGTTT }\end{array}$ & 339 & $\mathrm{R}=\mathrm{WKY}=\mathrm{SHR}>\mathrm{S}=\mathrm{MNS}$ \\
\hline ETA & 19 & *SSR & U02093 & $\begin{array}{l}\text { GCTAAGTAGCAAGTGTGGGAGG } \\
\text { TCTGTGGTTACTCTCTATGG }\end{array}$ & 225 & WKY $=$ SHR $>$ S $=$ MNS $=$ LEW \\
\hline ETB & 15 & *SSR & U02094 & $\begin{array}{l}\text { GTGACGTTAAGTGCCACTATGG } \\
\text { ACGGAAAGGTAAAGATACCG }\end{array}$ & 226 & $\mathrm{AS}=\mathrm{LEW}=\mathrm{S}=\mathrm{MNS}>\mathrm{WKY}=\mathrm{SHR}$ \\
\hline GLUTB & 5 & SSR & M22061 & $\begin{array}{l}\text { AAGTCCCGTGTTGGATAAGG } \\
\text { TCTGTCTAGTCCATGCCTGT }\end{array}$ & 206 & LEW $=$ MNS $>$ S $=$ WKY $>$ R \\
\hline HEOXG & 19 & SSR & J02722 & $\begin{array}{l}\text { CCACCACACTTGGCTTCTAT } \\
\text { CAGAGTGAAGACATCCAGGG }\end{array}$ & 160 & $\mathrm{~S}=\mathrm{MNS}>\mathrm{SHR}>\mathrm{WKY}=\mathrm{LEW}$ \\
\hline PRL & 17 & SSR & J00766 & $\begin{array}{l}\text { TGTGAACTTGTGTGCCTGTG } \\
\text { CGCAGTCATTTTTAGAGC }\end{array}$ & 208 & $\mathrm{~S}=\mathrm{WKY}=\mathrm{MNS}>\mathrm{SHR}=\mathrm{LEW}$ \\
\hline SCN & 3 & SSR & X03639 & $\begin{array}{l}\text { TCTTACTCATCCACATGGCACC } \\
\text { GTGTTTGGCTGTAATTGGCG }\end{array}$ & 166 & MNS $>$ WKY $>$ S $>$ SHR \\
\hline SVS & 3 & SSR & $\mathrm{J} 05443$ & $\begin{array}{l}\text { CCAATGTGTGGATTACTCAC } \\
\text { ATACTGGCGAGAGATGAAGG }\end{array}$ & 155 & LEW $=$ SHR $>$ R $>$ S \\
\hline MITR735 & 5 & SSR & & Research Genetics & ${ }^{\ddagger} 150$ & $\mathrm{~S}>\mathrm{LEW}=\mathrm{MNS}=\mathrm{R}$ \\
\hline MITR834 & 17 & SSR & & Research Genetics & $\ddagger_{100}$ & $\mathrm{~S}=\mathrm{MNS}>\mathrm{WKY}=\mathrm{LEW}$ \\
\hline MITR1678 & 5 & SSR & & Research Genetics & ${ }^{ \pm} 100$ & LEW $=\mathrm{MNS}>\mathrm{WKY}>\mathrm{S}$ \\
\hline MITHITH & 17 & SSR & & Research Genetics & ${ }^{\ddagger} 180$ & LEW $>$ MNS $=\mathrm{WKY}=\mathrm{S}=\mathrm{BN}$ \\
\hline D4MIT14 & 5 & SSR & & Research Genetics & ${ }^{\ddagger} 150$ & $\mathrm{LEW}>\mathrm{S}$ \\
\hline
\end{tabular}

"Probe" refers to a PCR product used as a probe to screen a genomic rat library for clones containing SSR, which are simple sequence repeats used in the direct genotyping of the locus in question. * SSR indicates that the SSR is newly developed as a result of the present work. Some primers were purchased from Research Genetics (Huntsville, AL). ${ }^{\ddagger}$ Size based on an estimate on agarose gel. Abbreviations: ALPH2 III, $\alpha_{2}-$ adrenergic receptor class III; ACRM, acetylcholine receptor, m3 muscarinic; ANF, atrial natriuretic peptide; ANG, angiotensinogen; AT1, angiotensin II receptor $\mathrm{AT}_{1}$; CAT, catalase; D1A, dopamine-1A receptor; ELA, Elastase II; ET1, endothelin 1; ET2, endothelin 2/vasoactive intestine peptide (VIP); ET3, endothelin 3; ETA, endothelin receptor A; ETB, endothelin receptor B; GLUTB, glucose transporter, brain; HEOXG, heme-oxygenase; PRL, prolactin; SCN, sodium channel II; SVS, seminal vesicle secretion II protein; S, Dahl salt-sensitive strain; R, Dahl salt-resistant strain; MNS, Milan normotensive strain; LEW, LEWIS/NCr1BR strain; WKY, Wistar-Kyoto strain; SHR, spontaneously hypertensive strain; BN, Brown Norway strain; Murphy, sequence information provided by T. J. Murphy of Emory University. Primers were designed using the Primer Detective Program (Clontech).

or $(C T)_{n}$ SSR in or near the gene for each member of the ET system were digested with different restriction enzymes followed by subcloning until the fragment of interest became $<1 \mathrm{~kb}$. These clones were then sequenced. Flanking sequences around $(C A)_{n}$ and/or $(C T)_{n}$ repeats were used to design primers for PCR using the Primer Detective Program (Clontech, Palo Alto, CA). PCR of the SSR was done as given previously (7) except that labeled primers were used directly without purification.

Rat genomic clones containing SSR for ET1, ET2, ET3, ETA, and ETB were isolated. To verify that the genomic region containing the SSR was continuous and closely linked to the gene of the ET system in question, rather than being a chimera formed by ligating unlinked random genomic fragments during cloning, one of the three following, or any combinations of the three, criteria was applied.

First, all the clones positive for both a gene of interest and for containing a SSR were digested with restriction enzymes. Restriction mapping revealed that all such positive clones shared a similar restriction pattern and overlapped one another. Therefore, they were all cloned from the same chromosomal region. Secondly, after the flanking sequences around a SSR were determined and a PCR product was generated from a cloned genomic fragment containing the gene of interest and the SSR, the same PCR primers were used to amplify the remaining genomic clones also containing the same gene and SSR. Products of the same size were generated. If any one of these clones were a ran- domly formed chimera, it would contain the gene of interest ligated to a different SSR region. In cases where the region containing the SSR was close enough (e.g., $<3 \mathrm{~kb}$ ) to the coding region of the gene, PCR was carried out on undigested genomic DNA using one of the primers located inside the coding region and one of the primers flanking the SSR region. A PCR product of the expected size was generated. Finally, both PCR-based SSR polymorphisms and restriction fragment length polymorphisms (RFLP) were used to genotype ET1 and ET3 for the same $F_{2}$ rats (RFLP data was courtesy of Dr. G. Cicila, University of Missouri, Columbia, MO). The genotypes obtained from the two methods were concordant. Thus, all the SSR polymorphisms found in the present work are closely linked to the endothelin genes they represent. The SSR PCR primers are given in Table I.

Statistical analysis for genotyping and linkage. To eliminate genotyping errors, all homozygous genotypes were confirmed by retesting. When several loci on a particular chromosome region were genotyped, the MAPMAKER program was used to detect potential genotyping errors. If such possible errors were noted, the rats for the loci in question were genotyped again to either confirm or correct the results from the original genotyping.

ANOVA on blood pressure was done using SPSS programs (SPSS Inc., Chicago, IL). When testing for dominance of an allele at a given locus, one-way ANOVA was done followed by a contrast that compared the average value of the two homozygotes to that of the heterozy- 
Table It. Cosegregation Analysis of Systolic Blood Pressure ( $\mathrm{mmHg}$ ) with Loci Linked to, and Consisting of, Genes of the ET System on Rat Chromosomes in $F_{2}$ Male Populations and One Backcross Population Raised on a High-Salt (8\% NaCl) Diet

\begin{tabular}{|c|c|c|c|c|c|c|}
\hline \multirow{2}{*}{$\frac{\text { Chromosome }}{3}$} & \multirow{2}{*}{$\begin{array}{c}\text { Populations } \\
F_{2}(S \times S H R)\end{array}$} & \multirow[t]{2}{*}{ Locus } & \multicolumn{3}{|c|}{ Blood pressure and genotype } & \multirow[t]{2}{*}{$\begin{array}{l}\text { One-way } \\
\text { ANOVA }\end{array}$} \\
\hline & & & HH & HS & SS & \\
\hline & & ET3 & $159.8 \pm 4.70$ & $170.3 \pm 3.56$ & $177.0 \pm 6.34$ & 0.067 \\
\hline & & $n$ & 30 & 56 & 22 & \\
\hline & & SVS & $158.8 \pm 5.01$ & $171.6 \pm 3.59$ & $172.6 \pm 5.71$ & 0.10 \\
\hline & & $n$ & 26 & 55 & 27 & \\
\hline & & CAT & $172.8 \pm 4.79$ & $169.2 \pm 3.82$ & $163.3 \pm 5.42$ & 0.48 \\
\hline & & $n$ & 25 & 59 & 24 & \\
\hline & & $\mathrm{SCN}$ & $173.5 \pm 4.72$ & $170.0 \pm 3.84$ & $160.9 \pm 5.35$ & 0.23 \\
\hline & & $n$ & 26 & 57 & 25 & \\
\hline & $\mathrm{F}_{2}(\mathrm{~S} \times \mathrm{WKY})$ & & WW & WS & SS & \\
\hline & & ET3 & $173.6 \pm 3.39$ & $176.0 \pm 3.19$ & $170.7 \pm 3.32$ & 0.54 \\
\hline & & $n$ & 42 & 75 & 42 & \\
\hline & & ALPH2III & $177.5 \pm 4.33$ & $176.5 \pm 2.60$ & $165.5 \pm 3.83$ & 0.045 \\
\hline & & $n$ & 29 & 91 & 39 & \\
\hline & & $\mathrm{SCN}$ & $175.7 \pm 4.59$ & $174.9 \pm 2.63$ & $170.3 \pm 3.77$ & 0.58 \\
\hline & & $n$ & 35 & 86 & 38 & \\
\hline & $F_{1}(S \times R) \times S$ & & & RS & SS & \\
\hline & & SVS & & $160.5 \pm 2.89$ & $169.0 \pm 3.10$ & 0.053 \\
\hline & & $n$ & & 36 & 34 & \\
\hline \multirow[t]{29}{*}{5} & $\mathrm{~F}_{2}(\mathrm{~S} \times \mathrm{LEW})$ & & $\mathbf{L L}$ & LS & SS & \\
\hline & & MITR735 & $181.4 \pm 4.74$ & $187.4 \pm 4.00$ & $197.6 \pm 6.52$ & 0.095 \\
\hline & & $n$ & 45 & 65 & 41 & \\
\hline & & MITR1678 & $175.0 \pm 4.23$ & $191.6 \pm 4.13$ & $197.6 \pm 6.56$ & 0.0099 \\
\hline & & $n$ & 42 & 74 & 35 & \\
\hline & & GLUTB & $168.8 \pm 2.91$ & $192.0 \pm 4.44$ & $202.6 \pm 5.73$ & $<\underline{0.0001}$ \\
\hline & & $n$ & 41 & 72 & 38 & \\
\hline & & ET2 & $169.0 \pm 2.97$ & $193.5 \pm 4.44$ & $199.2 \pm 5.71$ & $\underline{0.0001}$ \\
\hline & & $n$ & 40 & 75 & 36 & \\
\hline & & ELA & $180.7 \pm 4.23$ & $191.9 \pm 4.77$ & $191.2 \pm 5.57$ & 0.19 \\
\hline & & $n$ & 48 & 68 & 35 & \\
\hline & & D4MIT14 & $184.8 \pm 4.30$ & $189.9 \pm 4.77$ & $191.1 \pm 6.24$ & 0.65 \\
\hline & & $n$ & 53 & 65 & 32 & \\
\hline & $\mathrm{F}_{2}(\mathrm{~S} \times \mathrm{MNS})$ & & MM & MS & SS & \\
\hline & & GLUTB & $171.3 \pm 3.23$ & $174.8 \pm 2.36$ & $173.6 \pm 3.00$ & 0.72 \\
\hline & & $n$ & 32 & 91 & 48 & \\
\hline & $\mathrm{F}_{2}(\mathrm{~S} \times \mathrm{R})$ & & $\mathbf{R R}$ & SR & SS & \\
\hline & & GLUTB & $156.0 \pm 3.44$ & $163.9 \pm 2.87$ & $169.5 \pm 4.09$ & 0.10 \\
\hline & & $n$ & 28 & 50 & 28 & \\
\hline & $F_{2}(S \times R) \times S$ & & & RS & SS & \\
\hline & & GLUTB & & $162.18 \pm 2.23$ & $170.1 \pm 4.14$ & 0.075 \\
\hline & & $n$ & & 40 & 28 & \\
\hline & $F_{2}(S \times W K Y)$ & & WW & WS & SS & \\
\hline & & MITR 1678 & $171.6 \pm 3.75$ & $172.8 \pm 2.85$ & $178.0 \pm 3.95$ & 0.33 \\
\hline & & $n$ & 42 & 78 & 39 & \\
\hline & & ET2 & $165.1 \pm 3.75$ & $175.2 \pm 2.88$ & $177.5 \pm 3.52$ & 0.071 \\
\hline & & $n$ & 31 & 78 & 50 & \\
\hline & & ANF & $166.0 \pm 3.15$ & $175.4 \pm 2.85$ & $177.4 \pm 3.93$ & 0.093 \\
\hline & & $n$ & 34 & 79 & 46 & \\
\hline \multirow[t]{9}{*}{15} & $\mathrm{~F}_{2}(\mathrm{~S} \times \mathrm{WKY})$ & & WW & WS & SS & \\
\hline & & ETB & $165.0 \pm 2.46$ & $175.5 \pm 2.96$ & $179.2 \pm 4.14$ & 0.022 \\
\hline & & $n$ & 39 & 75 & 45 & \\
\hline & $\mathrm{F}_{2}(\mathrm{~S} \times \mathrm{LEW})$ & & LL & LS & SS & \\
\hline & & ETB & $186.2 \pm 6.32$ & $192.7 \pm 4.21$ & $181.8 \pm 4.60$ & 0.26 \\
\hline & & $n$ & 34 & 77 & 40 & \\
\hline & $\mathrm{F}_{2}(\mathrm{~S} \times \mathrm{SHR})$ & & HH & HS & SS & \\
\hline & & ETB & $168.6 \pm 6.16$ & $169.2 \pm 3.27$ & $167.5 \pm 6.48$ & 0.097 \\
\hline & & $n$ & 25 & 61 & 21 & \\
\hline
\end{tabular}




\begin{tabular}{|c|c|c|c|c|c|c|}
\hline \multirow[t]{2}{*}{ Chromosome } & \multirow{2}{*}{$\begin{array}{c}\text { Populations } \\
F_{2}(S \times A S)\end{array}$} & \multirow[t]{2}{*}{ Locus } & \multicolumn{3}{|c|}{ Blood pressure and genotype } & \multirow[t]{2}{*}{$\begin{array}{l}\text { One-way } \\
\text { ANOVA }\end{array}$} \\
\hline & & & AA & AS & SS & \\
\hline & & ETB & $196.9 \pm 4.03$ & $199.0 \pm 2.90$ & $205.9 \pm 3.41$ & 0.18 \\
\hline & & $n$ & 43 & 88 & 57 & \\
\hline \multirow[t]{29}{*}{17} & $\mathrm{~F}_{2}(\mathrm{~S} \times \mathrm{LEW})$ & & LL & LS & SS & \\
\hline & & ET1 & $181.2 \pm 5.01$ & $191.0 \pm 4.18$ & $188.7 \pm 5.64$ & 0.42 \\
\hline & & $n$ & 31 & 78 & 42 & \\
\hline & & MITR834 & $173.1 \pm 4.56$ & $190.3 \pm 4.06$ & $194.4 \pm 5.55$ & 0.036 \\
\hline & & $n$ & 27 & 81 & 43 & \\
\hline & & AT1 & $174.1 \pm 5.28$ & $192.7 \pm 4.11$ & $190.1 \pm 5.24$ & 0.042 \\
\hline & & $n$ & 30 & 82 & 39 & $0.013^{*}$ \\
\hline & & PRL & $174.7 \pm 5.31$ & $192.6 \pm 4.17$ & $190.0 \pm 5.12$ & 0.054 \\
\hline & & $n$ & 30 & 81 & 40 & $0.017^{*}$ \\
\hline & & MITHITH & $168.9 \pm 4.72$ & $196.1 \pm 4.28$ & $187.3 \pm 4.61$ & $\underline{0.0014}$ \\
\hline & & $n$ & 29 & 79 & 43 & $0.0008^{*}$ \\
\hline & & ACRM & $171.5 \pm 4.84$ & $193.9 \pm 4.18$ & $189.5 \pm 5.12$ & $\overline{0.012}$ \\
\hline & & $n$ & 29 & 80 & 42 & $0.0036^{*}$ \\
\hline & $\mathrm{F}_{2}(\mathrm{~S} \times \mathrm{BN})$ & & BB & BS & SS & \\
\hline & & D1A & $172.0 \pm 3.07$ & $173.9 \pm 3.15$ & $178.6 \pm 5.86$ & 0.53 \\
\hline & & $n$ & 34 & 42 & 20 & \\
\hline & & ET1 & $172.9 \pm 3.08$ & $174.0 \pm 3.32$ & $176.3 \pm 5.17$ & 0.85 \\
\hline & & $n$ & 31 & 43 & 22 & \\
\hline & & AT1 & $171.6 \pm 3.32$ & $174.0 \pm 3.16$ & $178.0 \pm 5.07$ & 0.52 \\
\hline & & $n$ & 32 & 40 & 24 & \\
\hline & $\mathrm{F}_{2}(\mathrm{~S} \times \mathrm{MNS})$ & & MM & MS & SS & \\
\hline & & ACRM & $170.8 \pm 2.78$ & $176.6 \pm 2.38$ & $172.3 \pm 3.54$ & 0.27 \\
\hline & & $n$ & 51 & 79 & 41 & \\
\hline & $\mathrm{F}_{2}(\mathrm{~S} \times \mathrm{WKY})$ & & WW & WS & SS & \\
\hline & & ET1 & $172.4 \pm 3.75$ & $171.9 \pm 2.57$ & $179.3 \pm 4.10$ & 0.27 \\
\hline & & $n$ & 43 & 74 & 42 & \\
\hline & $F_{2}(S \times A S)$ & & AA & AS & SS & \\
\hline & & AT1 & $199.3 \pm 4.08$ & $200.8 \pm 2.75$ & $201.3 \pm 3.79$ & 0.93 \\
\hline & & $n$ & 43 & 96 & 49 & \\
\hline \multirow[t]{16}{*}{19} & $\mathrm{~F}_{2}(\mathrm{~S} \times \mathrm{WKY})$ & & Ww & WS & SS & \\
\hline & & HEOXG & $169.0 \pm 3.97$ & $174.1 \pm 2.70$ & $178.8 \pm 4.00$ & 0.23 \\
\hline & & $n$ & 38 & 85 & 36 & \\
\hline & & ETA & $169.1 \pm 3.19$ & $172.3 \pm 2.69$ & $182.1 \pm 4.46$ & 0.054 \\
\hline & & $n$ & 34 & 87 & 38 & \\
\hline & $\mathrm{F}_{2}(\mathrm{~S} \times \mathrm{SHR})$ & & HH & HS & SS & \\
\hline & & ETA & $166.1 \pm 5.23$ & $168.3 \pm 3.49$ & $172.8 \pm 6.35$ & 0.68 \\
\hline & & $n$ & 27 & 57 & 24 & \\
\hline & & ANG & $160.8 \pm 4.14$ & $168.8 \pm 3.77$ & $178.8 \pm 6.23$ & 0.054 \\
\hline & & $n$ & 31 & 53 & 24 & \\
\hline & $\mathrm{F}_{2}(\mathrm{~S} \times \mathrm{LEW})$ & & LL & LS & SS & \\
\hline & & ANG & $184.0 \pm 4.80$ & $187.1 \pm 4.37$ & $197.5 \pm 5.83$ & 0.23 \\
\hline & & $n$ & 46 & 73 & 32 & \\
\hline & $\mathrm{F}_{2}(\mathrm{~S} \times \mathrm{MNS})$ & & MM & MS & SS & \\
\hline & & ANG & $172.3 \pm 3.91$ & $172.1 \pm 2.02$ & $179.4 \pm 3.64$ & 0.20 \\
\hline & & $n$ & 37 & 96 & 34 & \\
\hline
\end{tabular}

* $P$ value assuming dominance of $\mathrm{S}$ allele. $n$, number of rats in each genotype. For designations of the loci and rat strains see the footnote to Table I. ANG was genotyped based on an RFLP with the restriction enzyme PvuII between the $S$ allele and the contrasting control alleles: A, allele for the AS strain; B, allele for the BN strain; H, allele for the SHR strain; L, allele for the LEW strain; M, allele for the MNS strain; W, allele for the WKY strain. ANOVA, analysis of variance; ANOVA values below a threshold of 0.002 are underlined.

gote. Linkage maps and QTL localization were done with MAPMAKER/ QTL programs $(27,28)$ obtained from Dr. Eric Lander (Whitehead Institute, Cambridge, MA). For genetic mapping of loci on a particular chromosome, two $F_{2}$ populations were combined when appropriate polymorphisms did not exist for all the loci in one $\mathrm{F}_{2}$ population. For mapping on chromosome $3, \mathrm{~F}_{2}(\mathrm{~S} \times \mathrm{SHR})$ and $\mathrm{F}_{2}(\mathrm{~S} \times \mathrm{WKY})$ were used; for mapping on chromosome $5, F_{2}(S \times L E W)$ and $F_{2}(S \times W K Y)$ were used; for mapping on chromosome $17, F_{2}(S \times L E W)$ and $F_{2}(S \times B N)$ 
were used; and for mapping on chromosome $19, \mathrm{~F}_{2}(\mathrm{~S} \times \mathrm{WKY})$ and $\mathrm{F}_{2}(\mathrm{~S} \times \mathrm{SHR})$ were used.

In QTL analysis of blood pressure in the rat, Jacob et al. (29) suggested that an LOD (base 10 logarithm of the odds favoring linkage) score of 3 should be set as the significance level to reasonably establish the existence of a QTL when many marker loci are involved. Based on their analysis as well as our own recent experience (5-9), it is also important to further investigate chromosomal regions with LOD scores between 2 and 3 by studying more flanking markers or by increasing the size of the study populations.

Chromosome localization using rat-mouse somatic hybrids. Chromosome localization was done using PCR reactions on DNA of ratmouse somatic cell hybrids obtained from Szpirer et al. (30).

\section{Results}

Identification and genetic mapping of a new QTL for blood pressure on rat chromosome 5. Using SSR markers, we found that the genetic locus for ET2, also known as vasoactive intestinal peptide, cosegregated strongly with the systolic blood pressure $(P=0.0001)$ in the $F_{2}$ population $\left[F_{2}(S \times L E W)\right]$ descended from a cross of the $S$ and LEW rats. As shown in Table II, the difference of the average blood pressure measurement between homozygous SS and homozygous LL at the ET2 locus was $30 \mathrm{mmHg}$ which is the largest difference in blood pressure between the SS homozygote and a contrasting homozygote observed for any loci in our work.

To ascertain whether the ET2 locus was linked to any of the loci already known to have strong effects on blood pressure, we determined its chromosome location. Three pieces of information showed that the ET2 locus was located on rat chromosome 5 where no blood pressure QTL has been previously identified. First of all, the human ET2 locus had previously been mapped to $1 \mathrm{p} 34$ (17). The human chromosome fragment containing $1 \mathrm{p} 34$ is homologous to rat chromosome 5(31). Secondly, analysis of rat-mouse somatic cell hybrids revealed that the ET2 locus was on rat chromosome 5. Finally, we genotyped in the $\mathrm{F}_{2}(\mathrm{~S} \times \mathrm{WKY})$ population the atrial natriuretic factor $(\mathrm{ATF})$ locus, which has been localized to rat chromosome 5 (32). The ET2 locus was also genotyped in the $\mathrm{F}_{2}(\mathrm{~S} \times \mathrm{WKY})$ population and was linked to the ANF locus by roughly 33 centiMorgan (Fig. 1). Therefore, a locus identical to or closely linked to the ET2 locus on rat chromosome 5 represented a new QTL responsible for the differences of systolic blood pressure between the $S$ and LEW strains.

To localize the position for the blood pressure QTL and to estimate the statistical confidence interval containing the QTL on chromosome 5 , we tested all the available polymorphic rat SSR markers on this chromosome in $\mathrm{F}_{2}(\mathrm{~S} \times \mathrm{LEW})(32,33)$. We also took advantage of the conserved synteny groups between rat chromosome 5 and mouse chromosome 4 (31-33). Of 20 mouse MapPairs purchased from Research Genetics for mouse chromosome 4, D4MIT14 was polymorphic between the S and LEW rats and was linked to ET2. Table II shows the results of the statistical analysis and Fig. 1 shows the results of genetic mapping. The QTL was localized by using the MAPMAKER/QTL
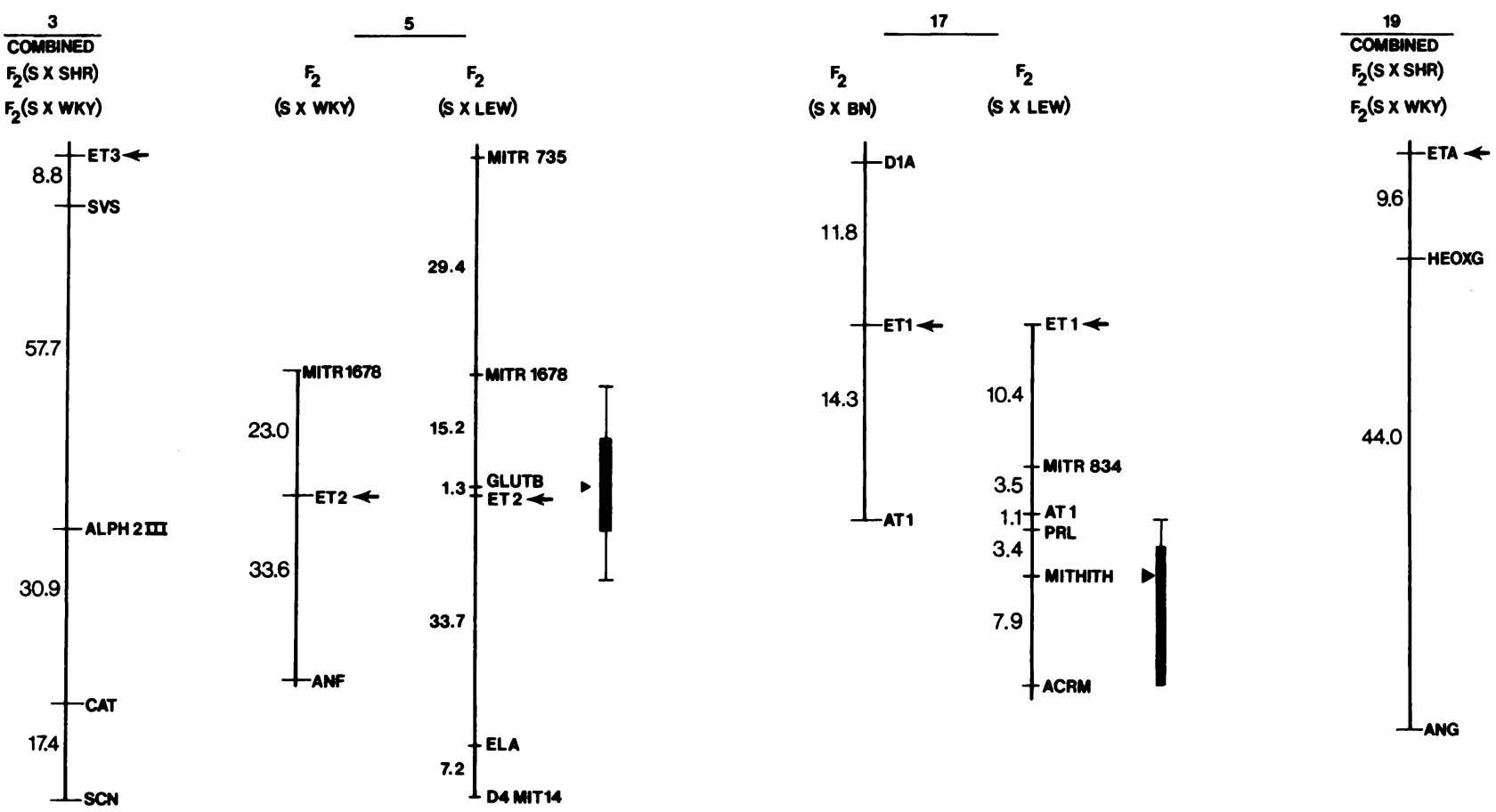

Figure 1. Identification of two blood pressure QTL on rat chromosomes 5 and 17, and genetic mapping for the genes of the rat ET system. The numbers on top denote rat chromosomes. The members of the ET system are indicated by leftward pointing arrows. The numbers along the vertical lines to the left of each chromosome indicate map units in centiMorgan using the Haldane correction. To the right of chromosomes 5 and 17 , the heavy vertical bar marks \pm 1 LOD unit for the QTL, the thin line is \pm 2 LOD units and the rightward pointing arrowheads indicates the QTL position (maximum LOD score) predicted by the MAPMAKER/QTL program $(27,28)$. Map distances within a chromosome map are drawn to scale, but maps are not drawn to the same scale among maps for chromosomes. The orders of the loci on each map except for chromosome 19 are, at least, 1,000-fold better than the next best orders. For chromosome 19, the linkage distances among the loci are correct, but the order of loci on the map cannot be definitely determined at present because of a lack of markers sufficiently close to one another. The orientation of the maps are arbitrary as the position of the centromere relative to the map is unknown. For strain and loci designations see footnote for Table I. 
program near the brain glucose transporter (GLUTB) locus with a maximum LOD score of 4.63. The QTL accounted for $\sim 13.2 \%$ of the total variance.

MITR1678, ET2, and ANF were tested for cosegregation with blood pressure in the $F_{2}(S \times W K Y)$ population. The GLUTB locus was tested for cosegregation with blood pressure in the $F_{2}(S \times M N S), F_{2}(S \times R)$ and a backcross $F_{1}(S \times R) \times S$ populations. All results were negative (Table II). Thus, cosegregation with blood pressure at a given locus is population dependent. A test of the ANF locus in the $F_{2}(S \times L E W)$ population was not possible for lack of polymorphisms between the $S$ and LEW strains.

Since it is an obvious candidate gene, the ET2 locus deserves a detailed molecular analysis such as making comparison of the ET2 gene of S with that of LEW for possible nucleotide differences. A preliminary sequencing revealed no nucleotide differences between $\mathrm{S}$ and LEW in the region of the ET2 gene coding for the ET2 peptide, or the exon-intron junctions flanking the ET2 peptide coding region.

Identification and genetic mapping of a new blood pressure $Q T L$ on rat chromosome 17 . During the cosegregation analysis and genetic mapping of ET1 in the $F_{2}(S \times L E W)$ population, we noticed two interesting features. First of all, the statistical significance level increases gradually from being nonsignificant at the ET1 locus $(P=0.42)$ to being weakly significant at the MITR834 $(P=0.036)$, angiotensin II receptor $(P=0.042)$ and prolactin (PRL) $(P=0.054)$ loci (Table II, Fig. 1). Secondly, there seems to be a dominant effect of the $S$ allele over the $L$ allele on blood pressure (i.e., the test for dominance is $P$ $=0.073$ at the PRL locus and $P=0.065$ at the angiotensin II receptor locus). When assuming dominance of the $S$ allele at both the PRL and angiotensin II receptor loci, the significance level for cosegregation with blood pressure improved (Table II). There were two possibilities for the weak cosegregation of this region with blood pressure: either the weak statistical result was a false positive or this region was next to a major blood pressure QTL beyond the PRL locus, with PRL marking one edge. If the second explanation were true, one should be able to find markers distal to PRL that strongly cosegregate with blood pressure.

Indeed, as we mapped and then tested more markers beyond the PRL locus, i.e., down rat chromosome 17 in Fig. 1, the statistical significance level reached a maximum at the MITHITH locus $(P=0.0014)$ and dropped at the acetylcholine receptor locus $(P=0.012)$ (Table II). The dominance effect of the $\mathrm{S}$ allele was pronounced at the MITHITH locus $(P=0.002)$ and at the acetylcholine receptor locus $(P=0.019)$. Using the MAPMAKER/QTL program, a QTL was localized near the MITHITH locus with a maximum LOD score of 2.90 (Fig. 1). The QTL accounted for $\sim 8.5 \%$ of the total variance.

Given that the QTL on chromosomes 5 and 17 were detected in the $\mathrm{F}_{2}(\mathrm{~S} \times \mathrm{LEW})$ population, a logical question to ask is whether there is epistatic interaction between these two QTL. No interaction on blood pressure was found between the MITHITH and GLUTB loci by a $2 \times 3$ factorial analysis of variance (two loci, three genotypes) (data not shown).

Genotyping and mapping of the other members of the ET system. The genes for ET3, ETA, and ETB were genotyped for cosegregation with blood pressure in as many $F_{2}$ populations involving $S$ rats as polymorphisms at each locus allowed. The results are shown in Table II. ETB had a $P$ value of 0.022 in the $\mathrm{F}_{2}(\mathrm{~S} \times \mathrm{WKY})$ population, which, by itself, is insufficient to establish a genetic effect on blood pressure. The loci for ET3 and ETA per se did not cosegregate with blood pressure in the populations tested.

To localize ET3, ETA, and ETB onto rat chromosomes we employed linkage analysis and/or a panel of rat-mouse somatic cell hybrids. Fig. 1 gives the results of chromosomal assignment and linkage to all the genes of the endothelin system except ETB. Among them, the initial assignment of ET1 was noteworthy. Since the human ET1 was assigned to 6p23-p24 (17) and the human chromosomal fragment containing 6p23-p24 is homologous to the portion of rat chromosome 17 marked by the PRL locus $(31,32)$, it is logical that one should find a genetic linkage relationship between PRL and ET1. Indeed, ET1 and PRL were linked by 15 centiMorgan in the rat. The assignment of ETB to chromosome 15 was achieved only by the analysis of rat-mouse somatic cell hybrids and is, therefore, provisional until confirmed by other independent tests.

Based on the analysis using the MAPMAKER program, the orders of the loci on each chromosome map in Fig. 1 except for chromosome 19 are the best orders, and are at least 1,000-fold better than the next best orders. The orders of loci on chromosome 5 and 17 have also been verified by scoring the markers in rats with chromosome crossovers in backcross breeding experiments (data not shown).

\section{Discussion}

The strong cosegregation of GLUTB and ET2 (Fig. 1, Table II) with systolic blood pressure in the $\mathrm{F}_{2}(\mathrm{~S} \times \mathrm{LEW})$ population and localization of a QTL with chromosome 5 markers provided convincing evidence that a blood pressure QTL is present on rat chromosome 5. This QTL is at least closely linked to, or may be, the ET2 locus itself. On the other hand, the ET2 locus may simply be a marker and the actual blood pressure QTL could be a completely different locus closely linked to ET2. The renin locus is a case in point. Even though renin cosegregated with blood pressure very strongly $(5,6,23)$ in segregating populations derived form the $S$ and $R$ rats, there were no nucleotide differences in the coding and $5^{\prime}$ regulatory sequences between the $S$ and $R$ rats (34). Therefore, the renin locus is probably a marker for a blood pressure QTL on rat chromosome 13 rather than the QTL itself.

Because ET2 did cosegregate with blood pressure in the $\mathrm{F}_{2}(\mathrm{~S} \times \mathrm{LEW})$ population, but did not cosegregate with blood pressure in the $\mathrm{F}_{2}(\mathrm{~S} \times \mathrm{WKY})$ population, and because GLUTB did not cosegregate with blood pressure in the $\mathrm{F}_{2}(\mathrm{~S} \times \mathrm{MNS})$ and $F_{2}(S \times R)$ populations, or in $F_{1}(S \times R) \times S$ population, the effect of this QTL on chromosome 5 is responsible for the difference in a component of blood pressure only between the $S$ and LEW rats. This type of population dependence has been observed by us repeatedly $(7,8,23)$. Therefore, to test a locus for possible effects on blood pressure, a number of independent populations derived from different crosses should be analyzed.

The blood pressure QTL near the MITHITH locus on rat chromosome 17 is a newly discovered QTL that also deserves further study, e.g., using congenic strains. Interestingly, the two blood pressure QTL on chromosomes 5 and 17 were identified by two different approaches, reflecting two facets of studying such a QTL. The QTL on chromosome 5 was identified directly using the ET2 locus as the marker. It turned out that the ET2 locus is rather close to, possibly identical to, the QTL itself (Fig. 1). The QTL on chromosome 17, on the other hand, was 
identified by "walking" from an informative marker (PRL). If we had completely ignored the PRL locus without analyzing more markers near it because its $P$ value of 0.054 for blood pressure cosegregation was marginal at best, the QTL on chromosome 17 would not have been discovered.

It has to be stressed that using a single marker is inadequate for the localization of a blood pressure QTL. The ET2 marker alone is not sufficient in defining the chromosomal region where the QTL resides (Fig. 1). Because a cosegregation analysis based on statistics can, at best, localize a QTL to a broad chromosome region (35), the necessity of defining the chromosomal interval for the QTL becomes evident if one wants to construct congenic strains to confirm the presence of a QTL, and further narrow the QTL location to a smaller chromosomal region for positional cloning. Without fine mapping information around the QTL, it is impossible to know how large a chromosomal region around the candidate locus should be, or actually is, included in the construction of congenic strains. In addition, the chromosomal region containing the QTL should be marked by polymorphic loci densely spaced in order to eliminate double crossovers during the construction of congenic strains. Otherwise, the allele of interest at the QTL may be lost during breeding.

As shown by genetic mapping, each member of the endothelin system is located on a different rat chromosome. It is worth noting that almost all of them are linked to other genetic loci coding for products of physiological importance in the control of blood pressure. For example, ET3 is linked to one of genes for $\alpha_{2}$-adrenergic receptor, class III (ALPH2 III) (25), which mediates sympathoadrenal activity (36); ET2 is linked to the locus for ANF, which induces diuresis, natriuresis, and vasorelaxation (37); ET1 is linked to the dopamine-1A receptor, which is involved in sodium transport (38), and to angiotensin receptor A, which mediates the vasoconstrictive activity of angiotensin II (16, 39); and ETA is linked to angiotensinogen, which is the substrate for renin (16). Therefore, a caveat of employing the candidate gene approach to identify blood pressure QTL is that even if a QTL can be identified by this approach, for example the QTL on rat chromosome 5, the identity of the QTL at the molecular level is, by no means, equated to the candidate locus per se. In this regard, the candidate gene approach is no different from the approach using random markers distributed throughout the rat genome because so many candidates are available. In fact, the candidate approach can be viewed as a limited and selective usage of the random scanning approach.

A benefit of the candidate approach is, however, that those candidate loci which do not cosegregate with blood pressure in several different $F_{2}$ populations can be reasonably downgraded as candidates for genetic hypertension. Pertinent to the endothelin system, even though the cosegregation tests thus far carried out were not exhaustive by any means, there is no evidence that a blood pressure QTL is located in the immediate chromosomal vicinity of ETA or possibly ET1.

Numerous individual loci cosegregating with blood pressure $(5-9,23,29,40-51)$ have been found recently. In all cases no, or poorly defined, genetic maps were presented. It is our view that with the possible exception of $11 \beta$ hydroxylase (2-4, 9) the identity and function of none of the blood pressure QTL have been established in the rat. In the case of $11 \beta$-hydroxylase a well defined steroidogenic pattern $(2-4,9)$ and base changes resulting in meaningful amino acid substitutions $(9,52)$ that alter steroidogenesis (52) are known.
The QTL localized in our current study may help find the chromosome regions containing genetic determinants for blood pressure in humans. For example, since the fragment of rat chromosome 5 containing the blood pressure QTL is homologous to 1 p32-p36 of the human chromosome (31), one can begin to study markers in this region in human populations for cosegregation with blood pressure. A prominent marker is, logically, ET2. Interestingly, the 6-phosphogluconate dehydrogenase locus located on human chromosome 1 p36 cosegregated with the diastolic blood pressure in sib-pair analysis of humans (53). Further analysis with more markers in this chromosome region of humans is, therefore, warranted.

\section{Acknowledgments}

We thank Dr. T. J. Murphy of Emory University for providing unpublished AT1 genomic sequences, C. Szpirer and J. Szpirer for DNA of somatic cell hybrids, Dr. D. Ginn for the R genomic library, Dr. G. Cicila for RFLP analysis of ET 1 and ET 3 loci, and Dr. E. Remmers for helpful discussions.

This work was supported by grants from the National Institutes of Health.

\section{References}

1. Dannenberg, A. L., T. Drizd, M. J. Horan, S. G. Haynes, and P. J. Leverton. 1987. Progress in the battle against hypertension. Hypertension (Dallas). 10:226-233.

2. Rapp, J. P., and L. K. Dahl. 1972. Mendelian inheritance of 18- and 11 $\beta$ steroid hydroxylase activities in the adrenals of rats genetically susceptible or resistant to hypertension. Endocrinology. 90:1435-1446.

3. Rapp, J. P., and L. K. Dahl. 1972. Possible role of 18-hydroxy-deoxycorticosterone in hypertension. Nature (Lond.). 237:338-339.

4. Rapp, J. P., and L. K. Dahl. 1976. Mutant forms of cytochromic P-450 controlling both 18 - and $11 \beta$-steroid hydroxylation in the rat. Biochemistry. 15:1235-1242.

5 Rapp, J. P., S.-M. Wang, and H. Dene. 1989. A genetic polymorphism in the renin gene of Dahl rats cosegregates with blood pressure. Science (Wash. DC). 243:542-544.

6. Rapp, J. P., S.-M. Wang, and H. Dene. 1990. Effect of genetic background on cosegregation of renin alleles and blood pressure in Dahl rats. Am. J. Hypertens. 3:391-396.

7. Deng, Y., and J. P. Rapp. 1992. Cosegregation of blood pressure with angiotensin converting enzyme and atrial natriuretic peptide receptor genes using Dahl salt-sensitive rats. Nature Genet. 1:267-272.

8. Harris, E. L., H. Dene, and J. P. Rapp. 1993. S gene and blood pressure cosegregation using Dahl salt-sensitive rats. Am. J. Hypertens. 6:330-334.

9. Cicila, G. T., J. P. Rapp, J. M. Wang, St. Lezin, E., S. C. Ng, and T. W. Kurtz. 1993. Linkage of $11 \beta$-hydroxylase mutations with altered steroid biosynthesis and blood pressure in the Dahl rat. Nature Genet. 3:346-353.

10. Yanagisawa, M., H. Kurihara, S. Kimura, Y. Tomobe, M. Kobayashi, Y. Mitsui, Y. Yazaki, K. Goto, and T. Masaki. 1988. A novel potent vasoconstrictor peptide produced by vascular endothelial cells. Nature (Lond.). 332:411-415.

11. Sakurai, T., M. Yanagisawa, A. Inoue, U. S. Ryan, S. Kimura, Y. Mitsui, K. Goto, and T. Masaki. 1991. cDNA cloning, sequence analysis and tissue distribution of rat preproendothelin-1 mRNA. Biochem. Biophys. Res. Commun. 175:4-47.

12. Bloch, K. D., C. C. Hong, R. L. Eddy, T. B. Shows, and T. Querternous. 1991. cDNA cloning and chromosomal assignment of the endothelin 2 gene: vasoactive intestinal contractor peptide is rat endothelin 2. Genomics. 10:236242.

13. Shiba, R., T. Sakurai, G. Yamada, H. Morimoto, A. Saito, T. Masaki, and K. Goto. 1992. Cloning and expression of rat preproendothelin-3 cDNA. Biochem. Biophys. Res. Commun. 186:588-594.

14. Sakurai, T., M. Yanagisawa, Y. Takuwa, H. Miyazaki, S. Kimura, K Goto, and T. Masaki. 1990. Cloning of a cDNA encoding a non-isopeptide-selective subtype of the endothelin receptor. Nature (Lond.). 348:732-735.

15. Lin, H. Y., E. H. Kaji, G. K. Winkel, H. E. Ives, and H. F. Lodish. 1991 Cloning and functional expression of a vascular smooth muscle endothelin 1 receptor. Proc. Natl. Acad. Sci. USA. 88:3185-3189.

16. Sealey, J. E., and J. H. Laragh. 1990. The renin-angiotensin-aldosterone system for normal regulation of blood pressure and sodium and potassium homeostasis. In Hypertension: Pathophysiology, Diagnosis and Management. J. H. Laragh and B. M. Brenner, editors. Raven Press, New York. 1287-1317.

17. Arinami, T., M. Ishikawa, A. Inoue, M. Yanagisawa, T. Masaki, M. C. Yoshida, and H. Hamaguchi. 1991. Chromosomal assignments of the human 
endothelin family genes: the endothelin-1 gene (EDN1) to 6p23-p24, the endothelin-2 gene (EDN2) to 1p34, and the endothelin-3 gene (EDN3) to 20q13.2q13.3. Am. J. Hum. Genet. 48:990-996.

18. Hoehe, M. R., H. Ehrenreich, B. Otterud, L. Caenazzo, R. Plaetke, H. Zander, and M. Leppert. 1993. The human endothelin-1 gene (EDN1) encoding a peptide with potent vasoactive properties maps distal to HLA on chromosome arm 6p in close linkage to D6S89. Cytogenet. Cell Genet. 62:131-135.

19. Cyr, C., K. Huebner, T. Druck, and R. Kris. 1991. Cloning and chromosomal localization of a human endothelin ETA receptor. Biochem. Biophys. Res. Commun. 181:184-190.

20. Hosoda, K., K. Nakao, N. Tamura, H. Arai, Y. Ogawa, S. Suga, S. Nakanishi, and H. Imura. 1992. Organization, structure, chromosomal assignment, and expression of the gene encoding the human endothelin-A receptor. J. Biol. Chem. 267:18797-18804.

21. Berge, K. E., and K. Berg. 1992. No effect of a TaqI polymorphism in DNA at the endothelin I (EDN1) locus on normal blood pressure level or variability. Clin. Genet. 41:90-95.

22. Cicila, G. T., J. P. Rapp, K. D. Bock, S. E. Lezin, T. W. Kurtz, C. C. Hong T. Quertermous, and S. C. Ng. 1992. Cosegregation of the endothelin-3 and $11 \beta$ hydroxylase loci with blood pressure is dependent upon genetic background in inbred Dahl rats. Hypertension (Dallas). 20:444. (Abstr.).

23. Rapp, J. P., H. Dene, and A. Y. Deng. 1994. Seven renin alleles in rats and their effect on blood pressure. J. Hypertens. 12:119-125.

24. Rapp, J. R., and H. Dene. 1985. Development and characteristics of inbred strains of Dahl salt-sensitive and salt-resistant rats. Hypertension (Dallas). 7:340-349.

25. Ginn, D. I., C. A. C. Baptista, K. Y. Alam, A. Y. Deng, H. Dene, H. Le, T. W. Kurtz, and J. P. Rapp. 1994. Genetic analysis of $\alpha 2$-adrenergic receptors and blood pressure using Dahl salt-sensitive rats. J. Hypertens. 12:127-135.

26. Sambrook, J., E. F. Fritsch, and T. Maniatis. 1989. Molecular Cloning: A Laboratory Manual. Cold Spring Harbor Laboratory Press, Cold Spring Harbor, NY.

27. Lander, E., P. Green, J. Abrahamson, A. Barlow, M. J. Daly, S. E. Lincoln, and L. Newburg. 1987. MAPMAKER: an interactive computer package for constructing primary genetic linkage maps of experimental and natural populations. Genomics. 1:174-181.

28. Lander, E., and D. Bostein. 1989. Mapping Mendelian factors underlying quantitative traits using RFLP linkage maps. Genetics. 121:185-199.

29. Jacob, H. J., K. Lindpaintner, S. E. Lincoln, K. Kusumi, R. K. Bunker, Y. Mao, D. Ganten, V. Dzau, and E. S. Lander. 1991. Genetic mapping of a gene causing hypertension in the stroke-prone spontaneously hypertensive rat. Cell. 67:213-224.

30. Szpirer, J., G. Levan, M. Thorn, and C. Szpirer. 1984. Gene mapping in the rat by mouse-rat cell hybrization: synteny of the albumin and alpha-fetoprotein genes and assignment to chromosome 14. Cytogenet. Cell Genet. 38:142149 .

31. Levan, G., J. Szpirer, C. Szpirer, K. Kinga, C. Hanson, and M. Q. Islam 1991. The gene map of the Norway rat (Rattus norvegicus) and comparative mapping with mouse and man. Genomics. 10:699-718.

32. Serikawa, T., T. Kuramoto, P. Hilbert, M. Mori, J. Ramada, C. Dubay, K. Lindpainter, D. Ganten, J. Guenet, G. M. Lathrop, et al. 1992. Rat gene mapping using PCR-analyzed microsatellites. Genetics. 131:701-721.

33. Goldmuntz, E. A., E. F. Remmers, H. Zha, P. Mathern, Y. Du, L. J. Crofford, and R. L. Wilder. 1993. Genetic map of seven polymorphic markers comprising a single linkage group on rat chromosome 5. Mammal. Genome. 4:670-675.

34. Alam, K. Y., Y. Wang, H. Dene, and J. P. Rapp. 1993. Renin gene nucleotide sequence of coding and regulatory regions in Dahl rats. Clin. Exp. Hypertens. 15:599-614.

35. Darvasi, A., A. Weinreb, V. Minke, J. I. Weller, and M. Soller. 1993. Detecting marker-QTL linkage and estimating QTL gene effect and map location using a standard genetic map. Genetics. 134:943-951.
36. Michel, M. C., O.-E. Brodde, and P. A. Insel. 1990. Peripheral adrenergic receptors in hypertension. Hypertension (Dallas). 16:107-120.

37. deBold, A. H. H. B. Borenstein, A. T. Veress, and H. Sonnenberg. 1981. A rapid and potent natriuretic response to intravenous injection of atrial myocardial extract in rats. Life Sci. 28:89-94.

38. Lokhandwala, M. F., and P. J. Barrett. 1982. Cardiovascular dopamine receptors: physiological, pharmacological and therapeutic implications. J. Auton. Pharmacol. 4:189-215.

39. Murphy, T. J., R. W. Alexander, K. K. Griendling, M. S. Runge, and K. E. Bernstein. 1991. Isolation of a cDNA encoding the vascular type-1 angiotensin Il receptor. Nature (Lond.). 351:233-236.

40. Kurtz, T. W., L. Simonet, P. M. Kobra, S. Wolfe, L. Chan, and B. L. Hjelle. 1990. Cosegregation of the renin allele of the spontaneously hypertensive rat with an increase in blood pressure. J. Clin. Invest. 85:1328-1332.

41. Hilbert, P., K. Lindpaintner, J. S. Beckmann, T. Serikawa, F. Soubrier, C. Dubay, P. Cartwright, B. De Gouyon, D. Julier, S. Takahasi, et al. 1991. Chromosomal mapping of two genetic loci associated with blood-pressure regulation in heredity hypertensive rats. Nature (Lond.). 353:521-529.

42. Pravenec, M., V. Kren, J. Kunes, A. G. Scicli, O. A. Carretero, L. Simonet, and T. W. Kurtz. 1991. Cosegregation of blood pressure with a kallikrein gene family polymorphism. Hypertension (Dallas). 17:242-246.

43. Iwai, H., and T. Inagami. 1992. Identification of a candidate gene responsible for the high blood pressure of spontaneously hypertensive rats. J. Hypertens. 10:1155-1157.

44. Iwai, H., T. W. Kurtz, and T. Inagami. 1992. Further evidence of the SA gene is candidate gene contributing to the hypertension in spontaneously hypertensive rat. Biochem. Biophys. Res. Commun. 188:64-69.

45. Katsuya, T., J. Higaki, T. Miki, K. Kohara, H. Yagisawa, H. Tanase, H. Mikami, T. Serikawa, H. Nojima, and T. Ogihara. 1992. Hypotensive effect associated with a phospholipase C- $\delta 1$ gene mutation in the spontaneously hypertensive rat. Biochem. Biophys. Res. Commun. 187:1359-1366.

46. Hamet, P., D. Kong, M. Pravenec, J. Kunes, V. Kren, P. Klir, Y. Sun, and J. Tremblay. 1992. Restriction fragment length polymorphism of hsp70 gene, localization in the RT1 complex, is associated with hypertension in spontaneously hypertensive rats. Hypertension (Dallas). 19:611-614.

47. Dubay, C., M. Vincent, N. J. Samani, P. Hilbert, M. A. Kaiser, J. Beressi, Y. Kotelevtsev, J. S. Bechmann, R. Soubrier, J. Sassard, et al. 1993. Genetic determinants of diastolic and pulse pressure map to different loci in Lyon hypertensive rats. Nature Genet. 3:354-357.

48. Ely, D. L., H. Daneshvar, M. E. Turner, M. L. Johnson, and R. L. Salisburry. 1993. The hypertensive $Y$ chromosome elevates blood pressure in $F_{11}$ normotensive rats. Hypertension (Dallas). 21:1071-1075.

49. Nabika, T., Y. Nara, K. Ikeda, J. Endo, and Y. Yamori. 1993. A new genetic locus cosegregating with blood pressure in $F_{2}$ progeny obtained from stroke-prone spontaneously hypertensive rats and Wistar-Kyoto rats. J. Hypertens. 11:13-18.

50. Lindpaintner, K., P. Hilbert, D. Ganten, B. Nadal-Ginard, T. Inagami, and $H$. Iwai. 1993. Molecular genetics of the $S_{A}$-gene: cosegregation with hypertension and mapping to rat chromosome 1. J. Hypertens. 11:19-23.

51. Katsuya, T., J. Higaki, Y. Zhao, T. Miki, H. Mikami, T. Serikawa, and T. Ogihara. 1993. A neuropeptide $Y$ locus on chromosome 4 cosegregates with blood pressure in the spontaneously hypertensive rat. Biochem. Biophys. Res. Commun. 192:261-267.

52. Matsukawa, N., Y. Nonaka, J. Higaki, M. Nagano, H. Mikami, T. Ogihara, and M. Okamoto. 1993. Dahl's salt-resistant normotensive rat has mutations in cytochromic p450 (11 $)$, but the salt-sensitive hypertensive rat does not. J. Biol. Chem. 268:9117-9121.

53. Wilson, A. F., R. C. Elston, L. D. Tran, and R. M. Siervogel. 1991. Use of the robust sib-pair method to screen for single-locus, multiple-locus, and pleiotropic effects: application to traits related to hypertension. Am. J. Hum. Genet. 48:862-872. 